

\title{
Morphologic Features of Carotid Plaque Rupture Assessed by Optical Coherence Tomography
}

\author{
S. Shindo, K. Fujii, M. Shirakawa, K. Uchida, Y. Enomoto, T. Iwama, M. Kawasaki, Y. Ando, and S. Yoshimura
}

\begin{abstract}
BACKGROUND AND PURPOSE: Rupture of the plaque fibrous cap and subsequent thrombosis are the major causes of stroke. This study evaluated morphologic features of plaque rupture in the carotid artery by using optical coherence tomography in vivo.
\end{abstract}

MATERIALS AND METHODS: Thirty-six carotid plaques with high-grade stenosis were prospectively imaged by optical coherence tomography. "Plaque rupture" was defined as a plaque containing a cavity that had overlying residual fibrous caps. The fibrous cap thickness was measured at its thinnest part for both ruptured and nonruptured plaques. The distance between the minimum fibrous cap thickness site and the bifurcation point was also measured. Optical coherence tomography identified 24 ruptured and 12 nonruptured plaques.

RESULTS: Multiple ruptures were observed in 9 (38\%) patients: Six patients had 2 ruptures in the same plaque, 2 patients had 3 ruptures in the same plaque, and 1 patient had 5 ruptures in the same plaque. Most (84\%) of the fibrous cap disruptions were identified at the plaque shoulder and near the bifurcation point (within a 4.2-mm distance). The median thinnest cap thickness was $80 \mu \mathrm{m}$ (interquartile range, 70-100 $\mu \mathrm{m}$ ), and $95 \%$ of ruptured plaques had fibrous caps of $<130 \mu \mathrm{m}$. Receiver operating characteristic analysis revealed that a fibrous cap thickness of $<130 \mu \mathrm{m}$ was the critical threshold value for plaque rupture in the carotid artery.

CONCLUSIONS: Plaque rupture was common in high-grade stenosis and was located at the shoulder of the carotid plaque close to the bifurcation. A cap thickness of $<130 \mu \mathrm{m}$ was the threshold for plaque rupture in the carotid artery.

ABBREVIATION: OCT = optical coherence tomography

$\mathbf{R}$ upture of the fibrous cap and subsequent thrombosis are the major causes of cardiovascular events such as heart attack and stroke. ${ }^{1-3}$ In a previous study of sudden coronary death, a fibrous cap thickness of $65 \mu \mathrm{m}$ was chosen as a criterion of instability because for a cap to rupture, the average cap thickness was $23 \pm 19$ $\mu \mathrm{m} ; 95 \%$ of caps measured $<65 \mu \mathrm{m}$ within a limit of only 2 SDs. ${ }^{1}$ Therefore, the fibrous cap thickness of $<65 \mu \mathrm{m}$ is now widely accepted as the definition of in vivo coronary vulnerable plaque that is prone to rupture. Disruption of the fibrous cap is frequently observed in symptomatic carotid plaques ${ }^{4,5}$ and is strongly associated with an ulceration appearance on angiography, ${ }^{6}$ which is con-

Received January 6, 2015; accepted after revision March 23.

From the Department of Neurology (S.S., Y.A.), Graduate School of Medical Science, Kumamoto University, Kumamoto, Japan; Department of Neurosurgery (S.S. M.S., K.U., S.Y.) and Cardiovascular Division (K.F.), Hyogo College of Medicine, Nishinomiya, Japan; and Departments of Neurosurgery (Y.E., T.I.) and Cardiology (M.K.), Gifu University Graduate School of Medicine, Gifu, Japan.

Please address correspondence to Shinichi Yoshimura, MD, PhD, Hyogo College of Medicine, Department of Neurosurgery, Mukogawa-cho, Nishinomiya, Hyogo, 6638501, Japan; e-mail: shinyoshi523@me.com

http://dx.doi.org/10.3174/ajnr.A4404 sidered an independent predictor of stroke on long-term follow-up in patients with symptomatic severe carotid stenosis. ${ }^{7}$ Redgrave et $\mathrm{al}^{8}$ examined the cross-sections of plaques with high-grade carotid stenosis and found that the optimum fibrous cap thickness for discriminating ruptured and nonruptured plaques was $200 \mu \mathrm{m}$; thus, it appears that there is no clear threshold for classifying plaques that are prone to rupture in vivo.

Intravascular sonography, which is a widely used imaging method in the field of carotid artery intervention, has an axial resolution of $100-200 \mu \mathrm{m}$ and a lateral resolution of $250 \mu \mathrm{m} .{ }^{9}$ Although it can visualize deep structures, intravascular sonography is not a suitable imaging technique for the detection of thin fibrous caps because its resolution is too low. Optical coherence tomography (OCT) has been introduced recently as a high-resolution imaging method. ${ }^{10,11}$ The typical OCT image has an axial resolution of $10 \mu \mathrm{m}$, approximately 10 times higher than that of any other clinically available diagnostic imaging technique, such as intravascular sonography. OCT provides an accurate representation of the thickness of the 
fibrous cap that could not be measured by other imaging modalities. ${ }^{12}$ In the present study, we evaluated the morphologic features of ruptured plaques in the carotid artery by using OCT.

\section{MATERIALS AND METHODS Study Population}

Between March 2012 and November 2013, a prospective but nonconsecutive series of 38 carotid arteries in 36 patients who were scheduled for carotid artery stenting to treat a high-grade stenosis in previously untreated carotid arteries underwent diagnostic OCT examinations to evaluate plaque morphology. OCT was performed only when carotid artery stenting was planned under proximal protection methods, due to the need for continuous injection of saline and contrast through the guiding catheter to remove blood from the FOV. Patients with a moderate stenosis at the proximal common carotid artery, a very tight stenosis at the target lesion, and intramural thrombus suspected on the basis of other modalities were not enrolled in this study because of the potential difficulty in acquiring and interpreting OCT images with such conditions. OCT examinations were performed for 38 carotid arteries in 36 patients, with 2 patients undergoing bilateral carotid artery stenting. Two patients were excluded because of poor OCT images. Finally, 36 carotid arteries in 34 patients were considered eligible for performing OCT image assessments. The grade of carotid stenosis was assessed by using angiography, ${ }^{13}$ and indications for carotid artery stenting were based on the Stenting and Angioplasty with Protection in Patients at High Risk for Endarterectomy trial. ${ }^{14}$ Because OCT is approved only for coronary arteries, its use in human carotid arteries was approved by our institutional ethics committee (No. 21-108), and the study protocol was submitted to an open-access data base (University Hospital Medical Information Network, trial number UMIN 000002808; http://www.umin.ac.jp/english/). Informed consent was obtained from all patients before participation.

\section{OCT Procedure}

Frequency domain OCT imaging was performed by using a C7-XR OCT imaging system (St. Jude Medical, St. Paul, Minnesota). A 9F guiding catheter with an occlusion balloon was inserted into the common carotid artery, and a guidewire with an occlusion balloon (GuardWire; Medtronic, Minneapolis, Minnesota) was introduced into the external carotid artery; or a 9F Mo.Ma system (Medtronic), which has 2 compliant balloons, was inserted where the distal balloon was located in the external carotid artery and the proximal balloon was located in the common carotid artery. Following a $\mathrm{Z}$ offset adjustment, an OCT imaging catheter (Dragonfly; St. Jude Medical) was advanced into the carotid artery beyond the stenotic site over a 0.014 -inch microguidewire. After the OCT catheter placement, a carefully debubbled mixture of saline and contrast (1:1 dilution) (iomeprol, Iomeron 300 ; Bracco, Milan, Italy) at $37^{\circ} \mathrm{C}$ was flushed through the guiding catheter at a rate of $6 \mathrm{~mL} / \mathrm{s}$ for a 5 -second period by using a motordriven injector. When a blood-free image was observed, the OCT imaging core was withdrawn by using a stand-alone electronic control of the pullback motor. We stored OCT images digitally for subsequent analysis.

\section{OCT Imaging Analysis}

All images were recorded digitally and analyzed by 2 independent investigators who were blinded to the clinical presentations and angiographic findings. Qualitative OCT assessment was performed for each artery by using previously published criteria. ${ }^{15}$ Plaques were classified as the following: 1) fibrous (homogeneous with high backscatter regions), 2) lipid-rich (low-signal region with diffuse border), or 3 ) calcified (low backscattering signal with a sharp border inside a plaque). For all nonruptured plaques that were determined lipid-rich with OCT, the fibrous cap thickness was measured at its thinnest part. The cap thicknesses were measured 3 times, and the average value was calculated. The distance between the minimum fibrous cap thickness site and the carotid bifurcation point was measured. "Plaque rupture" was defined as a plaque containing a cavity that was in contact with the lumen that had any overlying residual fibrous cap fragment. ${ }^{16}$ Rupture sites separated by a length of artery containing smooth lumen contours and no cavity were considered to represent different plaque ruptures. The thinnest cap thickness was measured at the thinnest part of the remnant of the disrupted fibrous cap. The distance between the plaque rupture site and the carotid bifurcation point was also measured. The largest intraplaque cavity was measured and extrapolated to the ruptured capsule area. Representative measurements of the thinnest part of ruptured and nonruptured caps are shown in Fig 1. "Thrombus" was defined as a backscattering protrusion into the carotid lumen with signal-intensity-free shadowing. ${ }^{17}$ "Neovascularization" was defined as a microchannel structure with no signal intensity without a connection to the vessel lumen that was present in $\geq 3$ continuous cross-sections of the OCT images. ${ }^{18}$

Identification of 2 separate plaques in the same artery (ie, infarct-related versus non-infarct-related lesion) required a $5-\mathrm{mm}$ reference segment between them; if not, they were considered to be part of 1 long lesion.

\section{Statistical Analysis}

JMP, Version 10.0 (SAS Institute, Cary, North Carolina) was used for all statistical analyses. Categoric data were expressed as absolute frequencies and percentages and were compared by using the $\chi^{2}$ or Fisher exact test, as appropriate. Continuous variables were expressed as either mean \pm SD for normally distributed variables or median (interquartile range, 25th to 75th percentiles) for non-normally distributed variables and were compared by using either an unpaired Student $t$ test or a Mann-Whitney $U$ test, respectively. Receiver operating characteristic analysis was used to determine the best cutoff cap thickness values for discriminating ruptured and nonruptured plaques. The $\kappa$ statistic was used to define the level of intra- and interobserver agreement in the identification of plaque rupture. The interobserver variability for measuring the fibrous cap thickness was assessed by linear regression analysis. $P<.05$ was regarded as a statistically significant difference.

\section{RESULTS}

The average time required for the OCT examination was $5.6 \pm 1.3$ minutes. No technical or neurologic complications were encountered during OCT procedures, though transient carotid artery occlusion and continuous infusion of saline and contrast media were nec- 
essary during the time required for imaging. The average pullback length imaged by OCT was $54 \mathrm{~mm}$. Among all of the 36 arteries examined, OCT identified 24 ruptured (67\%) and 12 nonruptured (33\%) plaques.

\section{Patient Characteristics}

Patient characteristics and angiographic findings are presented in Table 1 . There were no statistically significant differences in

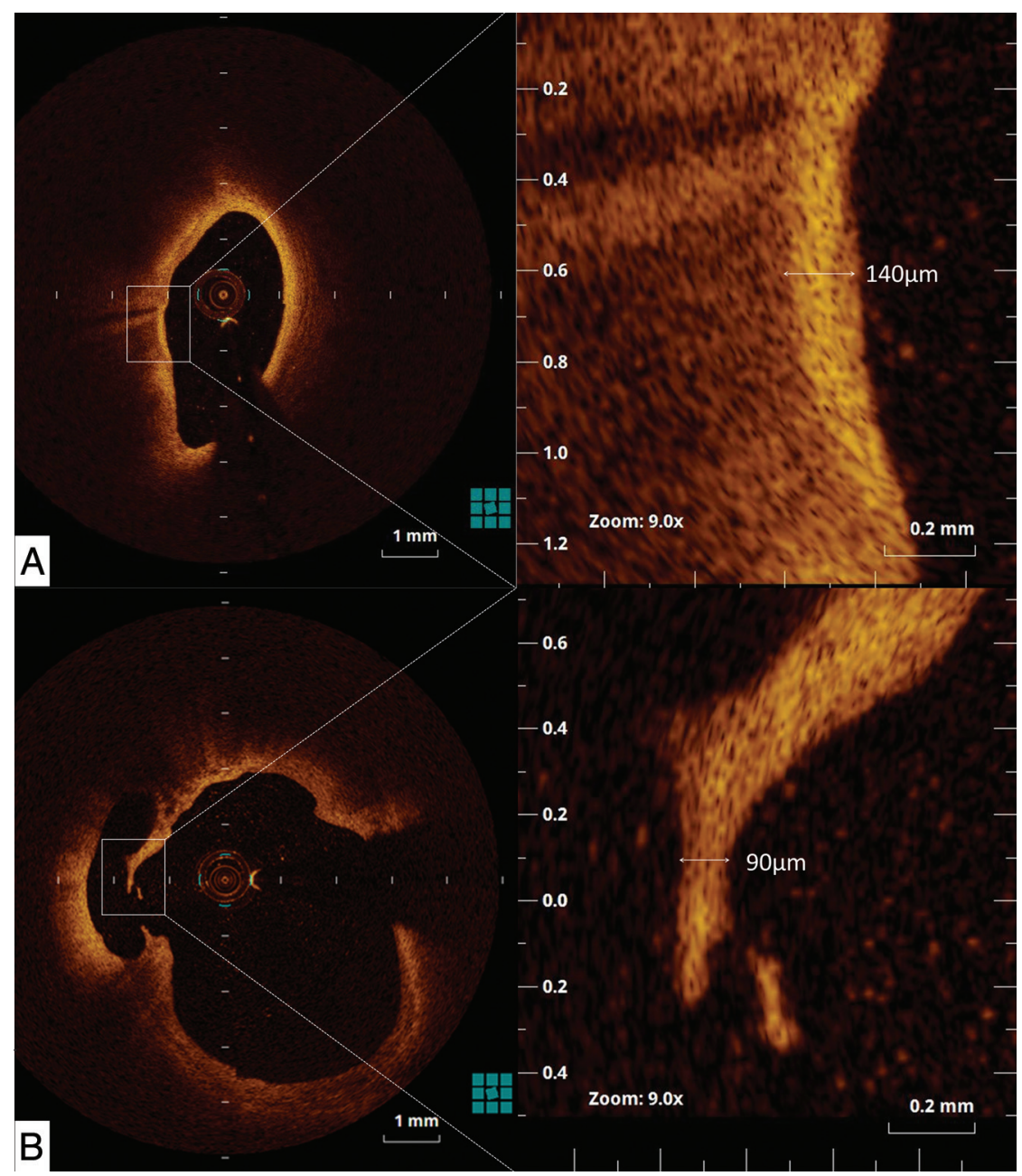

FIG 1. Representative measurements of nonruptured $(A)$ and ruptured $(B)$ fibrous cap thickness at the thinnest part. In these specimens, the thickness of the fibrous cap measured $140 \mu \mathrm{m}$ for a nonruptured lipid-rich plaque $(A)$, and $90 \mu \mathrm{m}$ for a ruptured plaque $(B)$ terms of age, sex, or other important stroke risk factors between patients with plaque rupture and those without plaque rupture.

\section{Fibrous Cap Thicknesses between Ruptured and Nonruptured Plaques}

Thirty-eight plaque ruptures in 24 arteries were identified by OCT. Of the 24 arteries with plaque ruptures, multiple ruptures were observed in 9 arteries (38\%): Six patients had 2 OCT ruptures in the same artery, 2 patients had 3 ruptures each in the same artery, and 1 patient had 5 ruptures in the same artery. In the remaining 12 arteries without plaque ruptures, OCT identified 12 nonruptured lipid-rich plaques in which the fibrous cap thickness could be reliably measured. OCT findings are summarized in Table 2. Among the findings presented, neovascularization was frequently identified in ruptured plaques compared with nonruptured plaques (54\% versus $17 \%, P<.03$ ). The median cap thickness at the thinnest part of the cap was significantly thinner in ruptured fibrous caps than in nonruptured fibrous caps $(80 \mu \mathrm{m}$ [interquartile range, $70-100 \mu \mathrm{m}$ ] versus $175 \mu \mathrm{m}$ [155-238 $\mu \mathrm{m}] ; P<.001)$ The fibrous cap thickness was thinner than $130 \mu \mathrm{m}$ in $95 \%$ of ruptured plaques and thicker than $130 \mu \mathrm{m}$ in $85 \%$ of nonruptured plaques. Figure 2 shows the frequency distribution of ruptured and nonruptured plaques according to the cap thickness measured at the thinnest part. On the basis of the receiver operating characteristic analysis, the optimal cap thickness for predicting plaque rupture was $<130 \mu \mathrm{m}$ (Fig 3 ).

The $\kappa$ statistic for intraobserver and interobserver variability for plaque rupture imaging was 1.00 and 1.00 , respec-

Table 1: Patient and angiographic characteristics ${ }^{a}$

\begin{tabular}{lccc}
\hline & Ruptured Plaques $(\boldsymbol{n}=\mathbf{2 4})$ & Nonruptured Plaques $(\boldsymbol{n}=12)$ & $72 \pm 6$ \\
\hline Age (yr) & $72 \pm 9$ & $10(83)$ & .85 \\
Male sex (\%) & $22(92)$ & & .47 \\
Imaged artery & & $10(83)$ \\
$\quad$ Right & $12(50)$ & $2(17)$ \\
$\quad$ Left & $12(50)$ & $5(42)$ \\
Symptomatic (\%) & $11(46)$ & $11(92)$ \\
Hypertension (\%) & $17(71)$ & $5(42)$ & .64 \\
Diabetes mellitus (\%) & $14(58)$ & $9(75)$ & .8 \\
Dyslipidemia (\%) & $16(67)$ & $75 \pm 14$ & .13 \\
Degree of stenosis (\%) & $79 \pm 12$ & $11(92)$ & .34 \\
Aspirin (\%) & $19(79)$ & $11(92)$ & .61 \\
Clopidogrel (\%) & $22(92 \%)$ & $4(33)$ & .48 \\
Cilostazol (\%) & $10(42)$ & .32 \\
\hline
\end{tabular}

${ }^{a}$ Data are given as mean \pm SD or No. (\%). 


\begin{tabular}{|c|c|c|c|}
\hline & Ruptured Plaques $(n=24)$ & Nonruptured Plaques $(n=12)$ & $P$ Value \\
\hline Plaque morphology & & & .19 \\
\hline Fibrous & $2(8)$ & $0(0)$ & \\
\hline Lipid-rich & $22(92)$ & $12(100)$ & \\
\hline Calcified & $0(0)$ & $0(0)$ & \\
\hline Thrombus (\%) & $9(38)$ & $3(25)$ & .45 \\
\hline Neovascularization (\%) & $13(54)$ & $2(17)$ & .03 \\
\hline
\end{tabular}

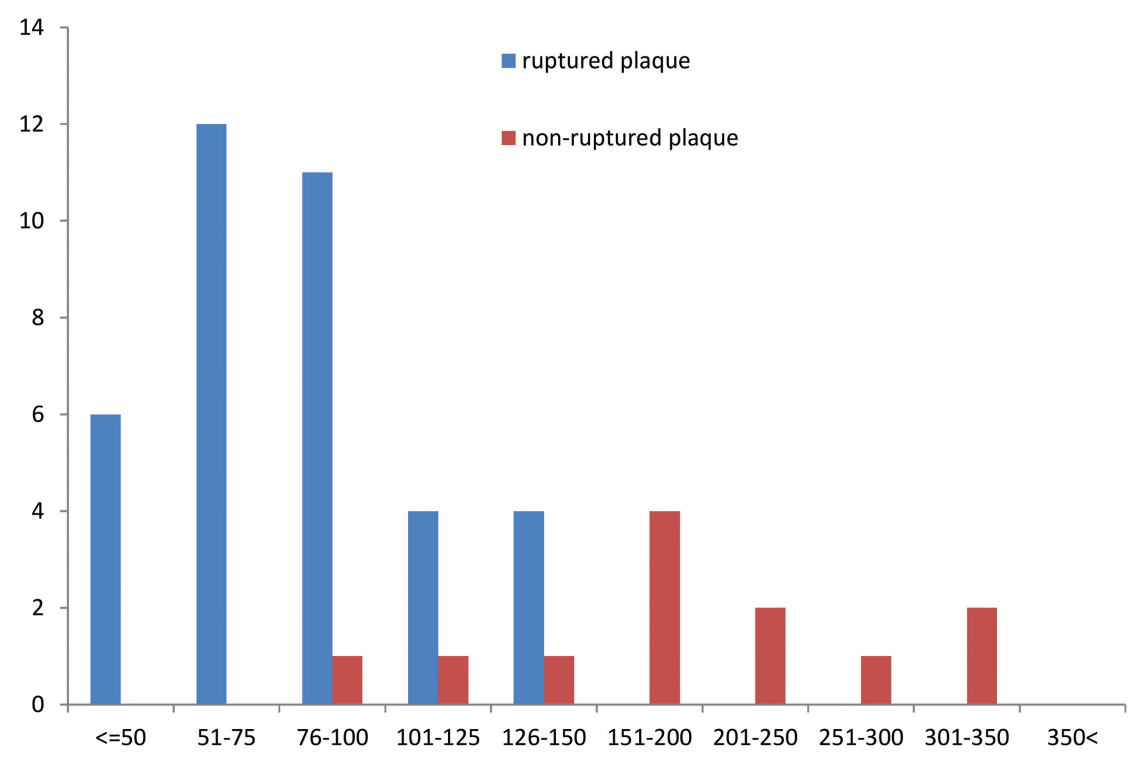

FIG 2. The frequency distribution of ruptured and nonruptured plaques according to the cap thickness at the thinnest part. Although the thinnest fibrous cap of ruptured plaques was $<150$ $\mu \mathrm{m}$ for all plaques, most nonruptured plaques had thicker fibrous caps.

tively. The measurement of fibrous cap thickness by OCT showed excellent interobserver reproducibility $(r=0.73, P<.01)$.

\section{Spatial Distribution and the Largest Ulcer Areas of Ruptured Plaques}

Eight ruptured sites $(21 \%)$ were located in the common carotid artery, and 30 (79\%), in the internal carotid artery. The median area of the ruptured plaque cavity measured $1.38 \mathrm{~mm}^{2}$ (interquartile range, $0.35-3.03 \mathrm{~mm}^{2}$ ). In all plaque ruptures, the site of the original tear in the fibrous cap could be identified; $26 \%$ (10/ 38) of tears appeared to have occurred in the center of the plaque, and the rest (74\%), at the shoulder of the plaque. The image section with plaque rupture was located at the narrowest lumen site in only $6(16 \%)$ plaques. A representative case that has plaque ruptures at the shoulder of the plaque is shown in Fig 4. The rupture site was proximal to the narrowest lumen site in 22 plaques $(58 \%)$ and distal to the narrowest lumen site in 10 plaques $(26 \%)$. In all plaques, the image section with the narrowest lumen area was near the bifurcation point. The median distance between the narrowest lumen site and the bifurcation point measured $4.2 \mathrm{~mm}$ (interquartile range, $2.2-13.8 \mathrm{~mm}$ ) in ruptured plaques and $6.7 \mathrm{~mm}$ (interquartile range, $3.0-8.8$ $\mathrm{mm})$ in nonruptured plaques $(P=.67)$. Similarly, the median distance between the fibrous cap thickness at the thinnest part and the bifurcation point was $4.6 \mathrm{~mm}$ (interquartile range, $0-12.0 \mathrm{~mm}$ ) in ruptured plaques and $5.0 \mathrm{~mm}$ (interquartile range, $1.3-10.5 \mathrm{~mm})$ in nonruptured plaques $(P=.82)$.

\section{DISCUSSION}

The main findings of the present study were the following: Plaque ruptures were frequently observed within carotid arteries with a high-grade stenosis; plaque ruptures may be multiple; fibrous cap thickness of $<130 \mu \mathrm{m}$ was the critical threshold for plaque rupture in the carotid artery; and most of the rupture tears were located at the shoulder of the carotid plaque but close to a side branch.

\section{Fibrous Cap Thicknesses between} Ruptured and Nonruptured Plaques Carotid plaque composition has been proposed as an important risk factor for thromboembolic events, such as stroke, giving rise to the concept of "vulnerable plaque." ${ }^{19}$ It has been suggested that thromboembolic phenomena are associated with thinning and subsequent rupture of the fibrous cap on the surface of atherosclerotic plaques, resulting in the release into the parent vessel of necrotic debris from the plaque substance. Several studies have established a correlation between plaque rupture and irregularity with clinical presentation and prognosis. ${ }^{4,20}$ Therefore, the identification of the fibrous cap is especially important because its thickness is a major determinant of plaque vulnerability in a lipid-rich carotid plaque. ${ }^{8}$ Therefore, the ability to measure the thickness of the fibrous cap accurately in vivo would help identify the carotid vulnerable plaque that is prone to rupture. OCT is a novel intravascular imaging technique, based on infrared light emission, that enables high-resolution arterial wall imaging, in the range of $10-20 \mu \mathrm{m}$. OCT penetration through a superficial lipidic component is less than that through fibrous tissue. Although the assessment of necrotic thickness would be an important piece of information, in most lesions, necrotic thickness cannot be measured because of insufficient OCT imaging penetration. In clinical practice, it may not be necessary to visualize the entire wall of a resection cavity; however, OCT analysis of entire suspicious areas of the resection cavity may have some benefit when choosing an optimal treatment strategy. However, the thickness of the fibrous cap is also a major determinant in the vulnerability of atherosclerotic plaque. ${ }^{21}$ OCT is the only imaging technique that can resolve intracoronary features on the scale of the thickness of a rupture-prone cap. Kume et $\mathrm{al}^{12}$ reported that OCT provides an accurate rep- 
resentation of the thickness of the fibrous cap that could not be measured by other imaging modalities.

Virmani et $\mathrm{al}^{1}$ defined plaque vulnerability on the basis of the actual thickness of the histologic section from measurements made of coronary plaque ruptures. A thickness of $65 \mu \mathrm{m}$ was considered a criterion of plaque instability in the coronary arteries because the average cap thickness was $23 \pm 19 \mu \mathrm{m}$ in ruptured plaques and $95 \%$ of the disrupted caps were $<65-\mu$ m-thick. Thus, the fibrous cap thickness of $<65 \mu \mathrm{m}$ has been widely used as the definition of in vivo coronary vulnerable plaque that is prone to rupture. Recently, Yonetsu et $\mathrm{al}^{22}$ evaluated the critical threshold of fibrous cap thickness for coronary plaque rupture by using OCT. They reported that the fibrous cap thickness was $<80$ $\mu \mathrm{m}$ in $95 \%$ of ruptured coronary plaques and the median fibrous cap thickness of ruptured plaques was $54 \mu \mathrm{m}$. Although the values of

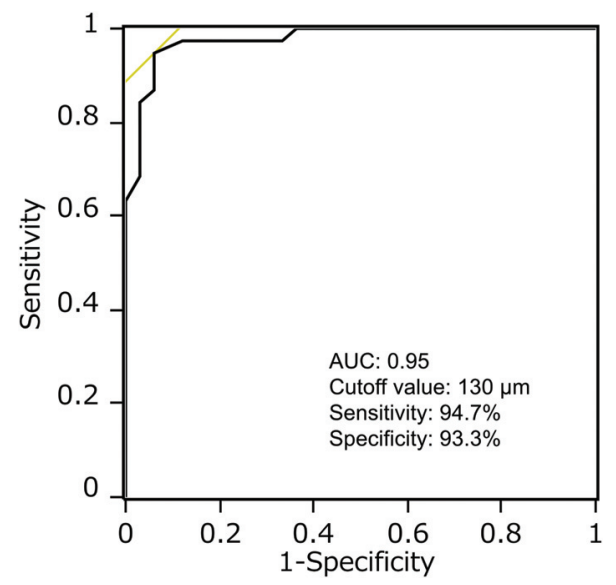

FIG 3. Receiver operating characteristic curves for measurements of fibrous cap thickness for the prediction of fibrous cap rupture. The optimal cap thickness value for predicting rupture was a cap thickness of $<130 \mu \mathrm{m}$ (area under the curve, 0.95; sensitivity, 94.7\%; and specificity, $93.3 \%$ ). the critical threshold for the disruption of the fibrous cap in coronary plaques are similar regardless of the methodology, there are large discrepancies in the values of the critical threshold for carotid plaques. The critical cap thickness of carotid plaques might be thicker than that of coronary plaques because the hemodynamic forces acting at the carotid bifurcation are greater in the carotid artery.

Redgrave et $\mathrm{al}^{8}$ conducted a histologic evaluation of $526 \mathrm{ca}$ rotid plaques from patients undergoing endarterectomy for symptomatic severe stenosis. They reported that the median cap thickness was $150 \mu \mathrm{m}$ in ruptured plaques, and the optimum cutoff for discriminating ruptured and nonruptured plaques was a minimum cap thickness of $<200 \mu \mathrm{m}$. On the contrary, a previous in vivo study by using sonography found that the critical cap thickness in carotid plaques was $460 \mu \mathrm{m} .{ }^{23}$ In the current OCT study, the median thickness of a fibrous cap at the thinnest part was $80 \mu \mathrm{m}$ and $95 \%$ of ruptured plaques had a fibrous cap thickness that was thinner than $130 \mu \mathrm{m}$. Possible reasons for the large discrepancy between the current OCT study and the previous sonography and postmortem studies are not entirely clear; however, possible points of difference may include study population variations and a small sample size of ruptured plaques in these studies. However, detection of plaques with complex morphology, such as a thin-cap fibroatheroma, may be more precise with OCT than with sonography because the higher resolution of OCT permits accurate measurement of the thin fibrous cap.

\section{Spatial Distribution of Ruptured Plaques}

From postmortem studies, it is known that fibrous caps vary widely in thickness, cellularity, matrix, strength, and stiffness, but they are often thinnest (and macrophage infiltration is greatest) at their shoulder regions where disruption most frequently occurs. ${ }^{24}$ The current study revealed that plaque ruptures were distinct
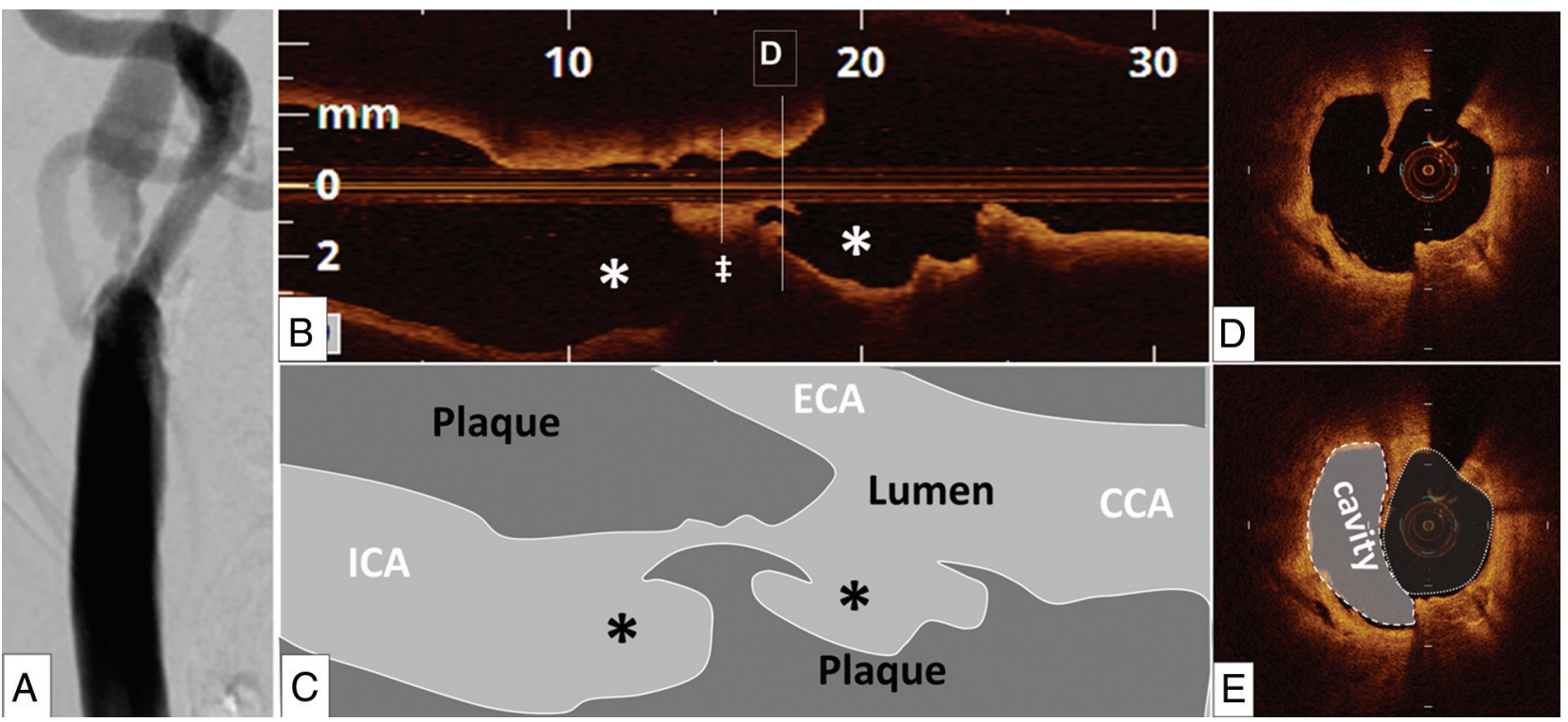

FIG 4. A representative patient (64-year-old man) with a $90 \%$ stenosis in the right internal carotid artery. A high-grade stenosis in the internal carotid artery was identified on the angiogram $(A)$. The disruptions of the plaques (asterisks) were identified near the bifurcation, but not at the narrowest lumen site (double dagger) in the optical coherence tomography longitudinal view ( $B$ and $C$ ). A ruptured plaque contains a cavity that communicates with the lumen with an overlying residual fibrous cap fragment ( $D$ and $E$ ). 
from minimum lumen sites in $74 \%$. These data confirm previous reports showing that plaque rupture occurs most often at the shoulder of the plaque. ${ }^{25}$ A previous histopathologic study demonstrated that inflammation of the atherosclerotic cap and shoulder of the plaque was a common and locally observed phenomenon in coronary arteries, similar to our findings. ${ }^{26}$ Activated metalloproteinases may be expressed more commonly at the shoulder of the vulnerable plaque. ${ }^{27-29}$ In the current study, 58\% of ruptured plaques were located in the proximal shoulder of the site with the most stenosis; the distance between the location of the minimum cap thickness and the bifurcation point measured $4.6 \mathrm{~mm}$ for ruptured plaques and $5.0 \mathrm{~mm}$ for nonruptured plaques. Severe stenoses produce flow turbulence that may increase stress on the nearby segment. In addition, endothelial cells near branches of a vessel have a reduced ability to repair wounds compared with cells from nonbifurcation regions. ${ }^{30}$

\section{Study Limitations}

Several limitations of the present study should be considered. First, this study was a single-center study with a relatively small study population. Further multicenter studies are required to reconfirm the results in a larger number of patients. Second, because the proximal segments of the target carotid arteries had to be occluded to remove blood from the imaging field during OCT image acquisition, some patients were not enrolled in this study if there was a potential difficulty in performing the proximal segment occlusion. Third, we also excluded patients who received emergent carotid artery stent placement because such patients must be treated as soon as possible. This selection bias might affect the results. Fourth, the penetration depth of OCT imaging is limited almost entirely by basic tissue optical properties and is the chief limitation of the technique, providing between 0.5 and $1.5 \mathrm{~mm}$ of imaging depth in most tissue types. Therefore, some ruptured plaques might be missed, especially when the cavity was filled by a lipidic component. Fifth, qualitative assessment of plaque composition by OCT may limit its diagnostic accuracy. However, this study confirmed that OCT demonstrated excellent reproducibility for the identification of plaque rupture. Finally, there are no data showing that OCT provides an accurate representation of the thickness of the fibrous cap in carotid plaques.

\section{CONCLUSIONS}

OCT showed that plaque rupture was common in carotid arteries with high-grade stenosis and was located at the shoulder of the carotid plaque close to a side branch. A fibrous cap thickness of $<130 \mu \mathrm{m}$ was the critical threshold for plaque rupture in the carotid artery. Future prospective large-scale in vivo studies are required to validate whether the fibrous cap thickness of $<130 \mu \mathrm{m}$ predicts plaque rupture and subsequent thromboembolic events for patients with carotid artery disease.

\section{REFERENCES}

1. Virmani R, Kolodgie FD, Burke AP, et al. Lessons from sudden coronary death: a comprehensive morphological classification scheme for atherosclerotic lesions. Arterioscler Thromb Vasc Biol 2000;20: 1262-75 CrossRef Medline

2. Burke AP, Farb A, Malcom GT, et al. Coronary risk factors and plaque morphology in men with coronary disease who died suddenly. N Engl J Med 1997;336:1276-82 CrossRef Medline

3. Farb A, Tang AL, Burke AP, et al. Sudden coronary death: frequency of active coronary lesions, inactive coronary lesions, and myocardial infarction. Circulation 1995;92:1701-09 CrossRef Medline

4. Carr S, Farb A, Pearce WH, et al. Atherosclerotic plaque rupture in symptomatic carotid artery stenosis. J Vasc Surg 1996;23:755-65; discussion 765-66 Medline

5. Saam T, Cai J, Ma L, et al. Comparison of symptomatic and asymptomatic atherosclerotic carotid plaque features with in vivo MR imaging. Radiology 2006;240:464-72 CrossRef Medline

6. Lovett JK, Gallagher PJ, Hands LJ, et al. Histological correlates of carotid plaque surface morphology on lumen contrast imaging. Circulation 2004;110:2190-97 CrossRef Medline

7. Rothwell PM, Villagra R, Gibson R, et al. Evidence of a chronic systemic cause of instability of atherosclerotic plaques. Lancet 2000; 355:19-24 CrossRef Medline

8. Redgrave JN, Gallagher P, Lovett JK, et al. Critical cap thickness and rupture in symptomatic carotid plaques: the Oxford plaque study. Stroke 2008;39:1722-29 CrossRef Medline

9. Nissen SE, Yock P. Intravascular ultrasound: novel pathophysiological insights and current clinical applications. Circulation 2001;103: 604-16 CrossRef Medline

10. Fujii K, Masutani M, Okumura T, et al. Frequency and predictor of coronary thin-cap fibroatheroma in patients with acute myocardial infarction and stable angina pectoris a 3-vessel optical coherence tomography study. J Am Coll Cardiol 2008;52:787-88 CrossRef Medline

11. Yoshimura S, Kawasaki M, Yamada K, et al. OCT of human carotid arterial plaques. JACC Cardiovasc Imaging 2011;4:432-36 CrossRef Medline

12. Kume T, Akasaka T, Kawamoto T, et al. Measurement of the thickness of the fibrous cap by optical coherence tomography. Am Heart J 2006;152.755.e1-4Medline

13. North American Symptomatic Carotid Endarterectomy Trial Collaborators. Beneficial effect of carotid endarterectomy in symptomatic patients with high-grade carotid stenosis. N Engl J Med 1991;325: 445-53 CrossRef Medline

14. Yadav JS, Wholey MH, Kuntz RE, et al; Stenting and Angioplasty with Protection in Patients at High Risk for Endarterectomy Investigators. Protected carotid-artery stenting versus endarterectomy in high-risk patients. N Engl J Med 2004;351:1493-501 CrossRef Medline

15. Tearney GJ, Regar E, Akasaka T, et al. Consensus standards for acquisition, measurement, and reporting of intravascular optical coherence tomography studies: a report from the International Working Group for Intravascular Optical Coherence Tomography Standardization and Validation. J Am Coll Cardiol 2012;59:1058-72 CrossRef Medline

16. Fukunaga M, Fujii K, Nakata T, et al. Multiple complex coronary atherosclerosis in diabetic patients with acute myocardial infarction: a three-vessel optical coherence tomography study. Eurointervention 2012;8:955-61 CrossRef Medline

17. Kume T, Akasaka T, Kawamoto T, et al. Assessment of coronary arterial thrombus by optical coherence tomography. Am J Cardiol 2006;97:1713-17 CrossRef Medline

18. Kitabata H, Tanaka A, Kubo T, et al. Relation of microchannel structure identified by optical coherence tomography to plaque vulnerability in patients with coronary artery disease. Am J Cardiol 2010; 105:1673-78 CrossRef Medline

19. Streifler JY, Eliasziw M, Fox AJ, et al. Angiographic detection of carotid plaque ulceration: comparison with surgical observations in a multicenter study-North American Symptomatic Carotid Endarterectomy Trial. Stroke 1994;25:1130-32 CrossRef Medline 
20. Toussaint JF, LaMuraglia GM, Southern JF, et al. Magnetic resonance images lipid, fibrous, calcified, hemorrhagic, and thrombotic components of human atherosclerosis in vivo. Circulation 1996;94: 932-38 CrossRef Medline

21. Naghavi M, Libby P, Falk E, et al. From vulnerable plaque to vulnerable patient: a call for new definitions and risk assessment strategies: Part I. Circulation 2003;108:1664-72 CrossRef Medline

22. Yonetsu T, Kakuta T, Lee T, et al. In vivo critical fibrous cap thickness for rupture-prone coronary plaques assessed by optical coherence tomography. Eur Heart J 2011;32:1251-59 CrossRef Medline

23. Devuyst G, Karapanayiotides T, Ruchat P, et al. Ultrasound measurement of the fibrous cap in symptomatic and asymptomatic atheromatous carotid plaques. Circulation 2005;111:2776-82 CrossRef Medline

24. Richardson PD, Davies MJ, Born GV. Influence of plaque configuration and stress distribution on fissuring of coronary atherosclerotic plaques. Lancet 1989;2:941-44 Medline

25. Galis ZS, Sukhova GK, Lark MW, et al. Increased expression of matrix metalloproteinases and matrix degrading activity in vulnerable regions of human atherosclerotic plaques. J Clin Invest 1994;94: 2493-503 CrossRef Medline
26. Pasterkamp G, Schoneveld AH, van der Wal AC, et al. Inflammation of the atherosclerotic cap and shoulder of the plaque is a common and locally observed feature in unruptured plaques of femoral and coronary arteries. Arterioscler Thromb Vasc Biol 1999;19:54-58 CrossRef Medline

27. Brown DL, Hibbs MS, Kearney M, et al. Identification of $\mathbf{9 2 - k D}$ gelatinase in human coronary atherosclerotic lesions: association of active enzyme synthesis with unstable angina. Circulation 1995;91: 2125-31 CrossRef Medline

28. de Kleijn DP, Sluijter JP, Smit J, et al. Furin and membrane type-1 metalloproteinase mRNA levels and activation of metalloproteinase-2 are associated with arterial remodeling. FEBS Lett 2001;501: 37-41 CrossRef Medline

29. Tang D, Teng Z, Canton G, et al. Sites of rupture in human atherosclerotic carotid plaques are associated with high structural stresses: an in vivo MRI-based 3d fluid-structure interaction study. Stroke 2009;40:3258-63 CrossRef Medline

30. Akong TA, Gotlieb AI. Reduced in vitro repair in endothelial cells harvested from the intercostal ostia of porcine thoracic aorta. Arterioscler Thromb Vasc Biol 1999;19:665-71 CrossRef Medline 